\title{
Study of wind forces on low-rise hip-roof building
}

\author{
A. Jameel ${ }^{1}$, H. Irtaza $^{2^{*}}$, M.A. Javed ${ }^{3}$ \\ ${ }^{1}$ University Polytechnic, Aligarth Muslim University, Aligarh - 202002, INDIA \\ ${ }^{2 *}$ Department of Civil Engineering, Aligarth Muslim University, Aligarh - 202002, INDIA \\ ${ }^{3}$ Department of Civil Engineering, Aligarth Muslim University, Aligarh - 202002, INDIA \\ ${ }^{*}$ Corresponding Author: e-mail: hirtaza.amu@gmail.com, Tel +91-8126710884
}

\begin{abstract}
A comprehensive numerical study of wind effects using Computational Fluid Dynamics (CFD) techniques on the low-rise hipped roof building is presented in this paper. Two Reynolds Averaged Navier-Stokes Equations (RANS) techniques such as the Standard $k-\varepsilon$ turbulence model and the Renormalization group (RNG) $k-\varepsilon$ turbulence model were adopted in this study to predict the wind loads and the flow patterns around the hip-roof building. The computed wind pressure coefficients on the roof of the hip-roof buildings were compared with the wind-tunnel data. It was found that the results obtained using RNG $k-\varepsilon$ turbulence model are in good agreement with that of the wind-tunnel data than the Standard $k-\varepsilon$ turbulence model. It was also found that the CFD techniques are an effective and alternative tool, less time consuming, easy-to-handle, as well as low cost approach for evaluation of wind effects in comparison to wind-tunnel experiments, using the above turbulence models and with the available resources.
\end{abstract}

Keywords: CFD, Computational Fluid Dynamics, Wind force, Hip-roof building, Low-rise building, RANS approach, Wind Engineering.

DOI: http://dx.doi.org/10.4314/ijest.v7i2.4

\section{Introduction}

A hip-roof, or hipped roof as shown in Fig. 1, is a type of roof where all sides slope downwards to the walls, usually with a fairly gentle slope. Thus, it is a house with no gables or other vertical sides to the roof. Hip roofs are thus commonly seen in places of heavy wind such as in hilly regions, coastal regions, etc. and are subjected to drag forces. Corners receive a relatively large outward pressure. A flat roof experiences an outward pressure or uplift, in addition to drag forces. The pressure on a pitched roof varies depending on different factors such as the slope of the roof and the building dimensions. Eaves and overhangs are affected by entrapped wind underneath them which leads to a pressure stagnation on them (Taher, 2010).

Wind flow is turbulent in nature and consists of many complex flow patterns. The field of wind engineering generally comes across with these types of flows. Wind pressures on buildings and structures depend upon the velocity profile and turbulence characteristics of the upcoming wind. These factors in turn depend on the roughness and general conformation of the upstream terrain (Bitsuamlak et al., 2004). Wind loads generally govern the lateral strength of a building and this aspect is more evident in areas of severe wind (Ahmad et al, 2002).

$\mathrm{Xu}$ et al. (1998) carried out wind-tunnel tests on the models of hip-roof building on a scale of 1:50 (prototype dimension $14 \mathrm{~m} \mathrm{x}$ $7 \mathrm{~m} \mathrm{x} 2.9 \mathrm{~m}$ eave height) with pitch $15^{\circ}, 20^{\circ}, 30^{\circ}$ and studied the wind pressures on the roof. The highest peak suction at the corner was experienced with a slope of $30^{\circ}$. The worst peak suctions are much smaller on the hip-roof than on the gable roof for $15^{\circ}$ and $20^{\circ}$ roof pitches. A wind-tunnel study of the effect of geometry of hip-roof building on wind pressures on low-rise hip-roof buildings were also carried out by Shakeel et al (S. Ahmad et al, 2002) taking the same dimensions of the models of Xu et al. He concluded that variation of overhang ratio $(0.17,0.26$ and 0.38$)$ on the hip roof with $30^{\circ}$ roof pitch have shown moderate effects on roof pressures. Both the overhang and aspect ratio were found to influence the magnitude and distribution of pressures on the hiproof. 
In the above studies, Xu et al and Shakeel et al did not place the pressure taps on the overhang portions, corner regions and sharp edges of the hip-roof building in their wind-tunnel experiments. This may be due to practical difficulty in placing and fixing of pressure taps in the overhang and ridge portions. The pressure coefficients measured were either extrapolated or interpolated in those regions by $\mathrm{Xu}$ et al and Shakeel et al. So, it is not always possible to plot the exact values of pressure coefficients in all regions using wind-tunnel data. The above discrepancies in the determination of pressure coefficients on the hip-roof building can be resolved by using computational fluid dynamics techniques.

Nowadays, Computational Wind Engineering (CWE) as a branch of CFD is rapidly superseding experimental work to evaluate the interaction between wind and structures numerically offering an alternative technique to practical applications. Earlier the fundamental errors in the numerical modeling of the turbulent component of fluid flow were one of the main reasons why CFD techniques had not been fully accepted by the Wind Engineering community. But, an improved understanding now exists for the development of large suctions near leading roof edges and roof corners; the modeling of these phenomena in the wind-tunnel remains a problem. Development of improved turbulence models like LK (Launder and Kato), MMK (Murakami, Mochida and Kondo) predicted value of turbulent viscosity ratios much closer to the real values of fully developed turbulent flows (Huang et al, 2007).

For evaluation of building performance, Tsou et al. (2001) presented the development process and results of several research projects for applying computational fluid dynamics (CFD) to architectural design. Studies done by He et al. (1997), Lien et al. (2004), Zhang et al. (2005) focus on simulating flow in different building arrangement or blocks by means of CFD. The purpose behind these works was to validate the numerical modeling and understand the interference effects of surrounding groups of buildings. Blocken et al. (2009) provided a brief overview of the status of the application of CFD in building performance simulation for the outdoor environment. Concluding that CFD offers some considerable advantages compared to wind tunnel testing and simplified empirical or semi-empirical equations, its practical application in at least wind driven rain, convective heat and mass transfer. These studies indicate that the upstream buildings play a significant role on wind loads and flow pattern around the test building in straight-line winds.

Design engineers usually determine wind loads with reference to the pressure coefficients from the code of practice, which in turn are based on data from the boundary layer wind tunnels. Actual field situations are not always treated in these codes, making wind-tunnel tests necessary to determine the wind loads. As detailed wind pressure coefficients on hip roof buildings are missing in most of the international codes including IS: 875-part 3 (1987) for the purpose of design. Therefore, an extensive research is needed to evaluate pressure coefficients on hip-roof building considering various building parameters and different terrain conditions.

Meecham et al (Meecham et al, 1991) performed aerodynamic studies on hip and gable roofs and concluded that there is little difference in overall lift and overturning loads; however, differences has been observed in local pressures and in the loads applied to the primary structural elements. And further added that, these differences appear to explain the improved survival of hip roofs.

Keeping all the above mentioned facts in view, the same hip-roof building is selected in the present study to observe the effect of various wind angle attack on the roof using CFD simulation. The result of present numerical investigation is also compared with the available wind-tunnel test results of Xu et al and Shakeel et al with that of the two RANS methods i.e. the Standard $k-\varepsilon$ and the RNG $k-\varepsilon$ for evaluation of wind forces on hip-roof building. In addition, the reasons to cause the differences between the experimental data and numerical results are also discussed.

\section{Present Study}

A geometric scale of 1:50 of a hip-roof building (prototype plan dimensions $14 \mathrm{~m} \mathrm{x} 7 \mathrm{~m}$ and $2.9 \mathrm{~m}$ eave height) with $30^{\circ}$ roof pitch was selected as the test building. The model dimension of the above building is $280 \mathrm{~mm}$ x $140 \mathrm{~mm}$ and $58 \mathrm{~mm}$ eave height as shown in Fig. 1. The building was simulated for different angle of incidence varying from $0^{\circ}$ to $90^{\circ}$ at an interval of 15 degrees. The data used for numerical simulation were taken from the experimental study of Shakeel et al (S. Ahmad et al, 2002) and is shown in Table 1. A similar experimental study was also done by Xu et al (Xu et al, 2002) on the hip-roof building and the data used by them is also shown in Table 1 .

Both Shakeel et al and $\mathrm{Xu}$ et al have used the same model in their experimental study but the experiments were performed in different wind-tunnels. In order to obtain the better agreement between experimental and numerical results, the boundary conditions adopted in the numerical simulations should be the same as those in the experiments, especially for inflow boundary conditions. Therefore, the inflow boundary conditions and other parameters from the experimental study of Shakeel et al have been used in all the simulations. The friction velocity $\left(u_{\tau}=0.567 \mathrm{~m} / \mathrm{s}\right)$ and ground roughness length $(9-10 \mathrm{~mm})$ were derived from the wind profile obtained from wind-tunnel experiments of Shakeel et al. The log law velocity profile has been simulated for the inlet boundary conditions for the CFD analysis from the simulated atmospheric boundary layer in the wind-tunnel study. The inlet wind profile is shown in the Fig. 2. The mean longitudinal wind speed profile of Shakeel et al measured in the wind tunnel is in good agreement with full-scale profile with a power-law exponent of 0.15 whereas in case of $\mathrm{Xu}$ et al the power law exponent is 0.14. 
Table 1. Summary of wind-tunnel data from the study of Shakeel et al and Xu et al

\begin{tabular}{|c|l|c|c|}
\hline S. No. & \multicolumn{1}{|c|}{ Parameters } & \multicolumn{2}{c|}{ Value from wind-tunnel data of } \\
\cline { 3 - 4 } & & Shakeel et al & Xu et al \\
\hline 1. & Mean Wind Speed & $10.7 \mathrm{~m} / \mathrm{s}$ & $10.1 \mathrm{~m} / \mathrm{s}$ \\
\hline 2. & Power Law Coefficient $(\alpha)$ & 0.15 & 0.14 \\
\hline 3. & Roughness Length $\left(Z_{\mathrm{o}}\right)$ & $9-10 \mathrm{~mm}$ & $10 \mathrm{~mm}$ \\
\hline 4. & Longitudinal Turbulence Intensity & $18 \%$ & $20 \%$ \\
\hline 5. & Integral length scale & $0.45 \mathrm{~m}$ & $0.8 \mathrm{~m}$ \\
\hline
\end{tabular}

\section{Turbulence models and numerical methods}

Computational fluid dynamic techniques such as the Reynolds Averaged Navier-Stokes Equations (RANS) models have been used to predict the wind flows around the hip-roof building. The Fluent code (Fluent 6.2.3 User Guide, 2006) has been used here, which provides variety of turbulence models such as the Standard $k-\varepsilon$ and the RNG $k-\varepsilon$ of the RANS technique. The Fluent code is based on the partial differential equation that govern the movement of viscous fluid i.e. the Navier Stokes equation (1) and the continuity equation (2).

$$
\rho \frac{D V}{D t}=-\nabla P+\frac{\partial}{\partial x_{j}}\left[\mu\left(\frac{\partial v_{i}}{\partial x_{j}}+\frac{\partial v_{j}}{\partial x_{i}}\right)\right]
$$

$\nabla V=0$

Where, $\rho$ is density, $D / D t$ is the substantial derivative, $\mathrm{V}$ is the velocity vector, $\mathrm{P}$ is the pressure and $\mu$ is the effective viscosity. There were many difficulties in simulating the flow around the sharp edge bluff body because of large Reynolds number, impinging at the front, remaining effect of flow obstacles at outflow boundary etc., while analyzing the flow using computational fluid dynamics techniques as reviewed by Murakami (Murakami et al, 1998). Many efforts have been devoted by various researchers to overcome the problems in turbulence modeling, the wall boundary conditions and the over production of turbulent kinetic energy near the sharp edges etc.

Both the Standard $k-\varepsilon$ and the $\mathrm{RNG}_{k-\varepsilon}$ have nearly similar forms with transport equations for ${ }_{k}$ (turbulent kinetic energy) and $\varepsilon$ (dissipation rate), however, there are major differences in calculating turbulent viscosity and the production and dissipation of turbulent kinetic energy while modeling turbulence. The standard $k_{-\varepsilon}$ model proposed by Launder and Spalding (Launder $e t$ al, 1972) is a semi-empirical model based on model transport equations for the turbulence kinetic energy and its dissipation rate. It has been recognized widely that the Standard $k-\varepsilon$ can predict the general wind conditions around building reasonably well except those in the separation regions above roof surface and side walls and can be attributed to the overestimation of turbulence energy. As the strengths and weaknesses of the Standard $k-\varepsilon$ model became known, improvements were made to the turbulence model to improve its performance and in this sequence the $\mathrm{RNG}_{k-\varepsilon}$ turbulence model by Yakhot et al (Yakhot et al, 1982) were developed.

The RNG-based $k_{-\varepsilon}$ turbulence model is derived using a rigorous statistical technique, called renormalization group theory, from the instantaneous Navier-Stokes equations. The RNG model has an additional term in its $\varepsilon$ equation that significantly improves the accuracy for rapidly strained flows. Effect of swirl on turbulence, analytical formula for turbulent Prandtl numbers and an analytically-derived differential formula for effective viscosity to accounts for low Reynolds number effect (analytical derivation results in a model with constants different from those in the standard $k-\varepsilon$ model) is also included in RNGbased $_{k-\varepsilon}$ turbulence model (Fluent 6.2.3 User Guide, 2006). These features make the $\mathrm{RNG}_{k-\varepsilon}$ model more accurate and reliable, gives better results for a wider class of flows than the Standard $k-\varepsilon$ model.

These models are commonly used in simulation of wind flows around bluff bodies. All the discretized equations are solved in a segregated manner with the Semi-Implicit Method for Pressure-Linked Equations (SIMPLE) algorithm. The SIMPLE algorithm uses a relationship between velocity and pressure corrections to enforce mass conservation and to obtain the pressure field. The SIMPLE algorithm substitutes the flux correction equations into the discrete continuity equation to obtain a discrete equation for the pressure correction in the cell. The second order implicit scheme is used for time discretization. Second order upwind discretization uses large stencils for $2^{\text {nd }}$ order accuracy, essential with triangular or tetrahedral meshes or when the flow is not aligned with the grid. The only drawback it has that if using second order upwind discretization then the convergence is slower (Gambit 2.6 User Guide, 2006).

\section{Computational Parameters}

The computational domain, coordinate definition and boundary conditions for the present study on the model of the hip-roof building are shown in Fig. 3 and Fig. 4. The reason for choosing a large computational domain is to eliminate the flow obstacle effect on the inflow and outflow boundary conditions. The Reynolds numbers involved in the simulations were in the range of 


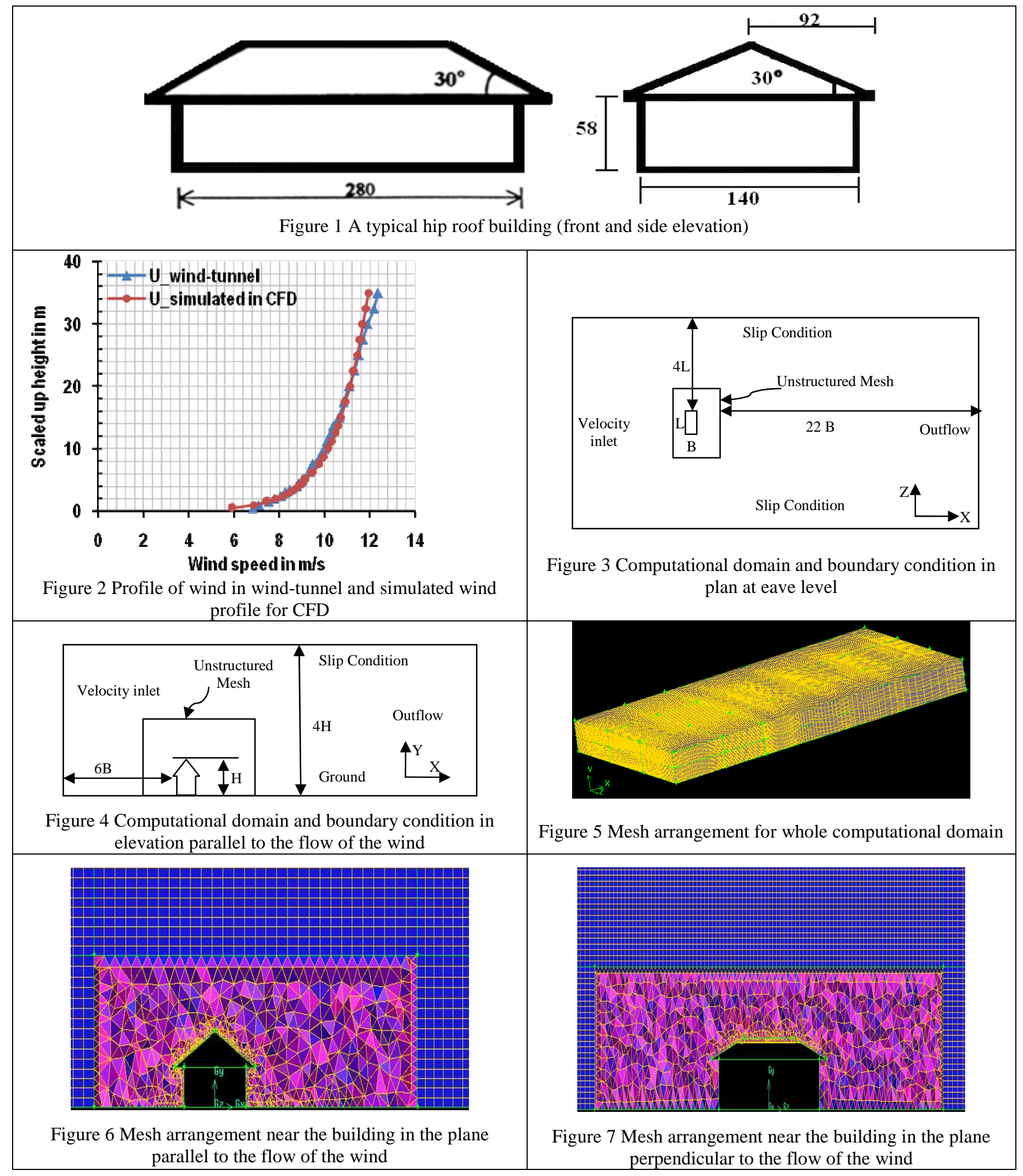


$1.35 \times 10^{5}$ to $2.4 \times 10^{5}$ for both wind-tunnel experiments and computational analyses. Although hip-roof building model is a very simple, its computational mesh generation is not straight forward in consideration of boundary layer conditions and wind attack angle. The problem occurs while generating quality mesh near the overhang portions, corners and on the roof where the direction of the roof slope changes. Besides this, the mesh number must be as low as possible as we could accept for efficient computation. The mesh generating software Gambit 2.6 (Gambit 2.6 User Guide, 2006) here is used for all the models. The primary characteristic of this mesh style is that the building model is nested in a rectangular cylinder much larger than itself. In the nesting rectangular cylinder, an unstructured mesh is generated while outside the nesting rectangular cylinder, the structured mesh is applied. This arrangement makes it easier to generate a mesh fine enough in the neighborhood of the building surfaces while keeping the mesh in zones far away from the building surfaces unchanged or in a proper coarser state. Another important advantage of this arrangement is that the mesh aligned to the building surfaces does not need to be stretched with the wall boundary layer grid as the structured mesh does. Various mesh schemes were generated and simulated for examining grid dependence. In all the mesh arrangements denser meshes were provided near the wall and mesh becomes rarer as we go away from the wall surface, while keeping the value of wall unit $y^{+}=\left(y^{+}=\rho u_{\tau} y / \mu\right)$ same in all the models. The standard wall functions were used and the values of $y^{+}$were kept in the range of 30-120 for all the models. Fig. 5, $6 \& 7$ shows the mesh arrangement for the hip-roof building model.

It is an unfortunate fact that no single turbulence model is universally accepted as being superior for all classes of problems. The choice of turbulence model depends on considerations such as the physics encompassed in the flow, the established practice for a specific class of problem, the level of accuracy required, the available computational resources, and the amount of time available for the simulation. To make the most appropriate choice of model for one application, one need to understand the capabilities and limitations of the various options. Large Eddy Simulation and Direct Numerical Simulation (DNS) are computationally very expensive and cannot be employed for all the runs.

It is very difficult to simulate the open wind characteristics exactly in a wind-tunnel. Even little differences in experimental conditions causes discrepancies between measurement results from different wind-tunnels. However, in order to obtain better agreement between experimental and numerical results, the boundary conditions adopted in the numerical simulations have been taken the same as those in the experiments, especially for the inflow boundary conditions.

The numerical time step for the RNG $k-\varepsilon$ model and the Standard $k-\varepsilon$ model was $2 \times 10^{-3} s ; 4000$ steps were iterated to obtain the time-averaged results. The statistical average of flow field was taken for the last 4000 steps (8s). In the present study mesh used is of the order of $10^{7}$ in each model. As standard wall function is used, so the value of $y^{+}$(y-plus) is managed within the range of 30 to 120 . This is necessary to avoid the need for very fine grids to resolve the large energy dissipation gradients in the near wall region and thus reduce the computational overheads of a given wall bounded problem.

\section{Results and discussions}

The numerical calibration and grid independent study were considered in the present study keeping wall unit $y^{+}$in the range of 30120 for the various cases of incident wind angles of $0^{\circ}$ to $90^{\circ}$, i.e. the mesh near the wall were not changed while the mesh away from the wall changed for grid independent study. These models were computed almost under the same mesh arrangements and under the same inflow boundary conditions as those simulated in the wind tunnel test of Shakeel et al. The building models in atmospheric boundary layers with Reynolds number larger than $10^{5}$ have been presented in this paper. The effectiveness of the turbulence models and numerical treatments for solving the practical problem with high Reynolds number were investigated in details.

Table 2. Maximum and minimum pressure coefficients on the hip-roof building

\begin{tabular}{|c|c|c|c|c|c|c|c|c|}
\hline \multirow{2}{*}{$\begin{array}{l}\text { Wind } \\
\text { Incident }\end{array}$} & \multicolumn{3}{|c|}{ Standard $k-\varepsilon$ Turbulence Model } & \multicolumn{4}{c|}{ RNG $k-\varepsilon$ Turbulence Model } \\
\cline { 2 - 9 } & $\begin{array}{c}\text { Maximum } \\
-\mathrm{ve}\end{array}$ & $\begin{array}{c}\text { Minimum }- \\
\mathrm{ve}\end{array}$ & $\begin{array}{c}\text { Maximum } \\
+\mathrm{ve}\end{array}$ & $\begin{array}{c}\text { Minimum } \\
+\mathrm{ve}\end{array}$ & $\begin{array}{c}\text { Maximum } \\
-\mathrm{ve}\end{array}$ & $\begin{array}{c}\text { Minimum } \\
-\mathrm{ve}\end{array}$ & $\begin{array}{c}\text { Maximum } \\
+\mathrm{ve}\end{array}$ & $\begin{array}{c}\text { Minimum } \\
+\mathrm{ve}\end{array}$ \\
\hline $0^{\circ}$ & -1.25 & - & 0.52 & - & -1.10 & - & 0.60 & - \\
\hline $15^{\circ}$ & -2.47 & -0.07 & - & - & -2.33 & -0.10 & - & - \\
\hline $30^{\circ}$ & -2.82 & -0.18 & - & - & -2.25 & -0.12 & - & - \\
\hline $45^{\circ}$ & -2.91 & -0.99 & - & - & -2.41 & -0.10 & - & - \\
\hline $60^{\circ}$ & -1.36 & - & 1.0 & - & -1.35 & - & 0.89 & - \\
\hline $75^{\circ}$ & -1.48 & - & 0.57 & - & -1.49 & - & 0.55 & - \\
\hline $90^{\circ}$ & -0.77 & - & 0.74 & - & -0.765 & - & 0.72 & - \\
\hline
\end{tabular}


Figs. 8 to 10 show the comparison of the wind pressure coefficients obtained from the numerical simulation using the Standard $k-\varepsilon$ and the RNG $k-\varepsilon$ turbulence model on the roof of the hip-roof building to that of the wind-tunnel study on the same model by Shakeel et al (S. Ahmad et al, 2002) and Xu et al (Xu et al, 2002) at $0^{\circ}, 45^{\circ}$ and $90^{\circ}$ wind incidence angle.

The numerical values of the mean pressure coefficients are compared with the available experimental data in order to check the accuracy of the CFD results. It can be seen that the numerical results fall in the range of the experimental data in general, but substantial discrepancies exists near the sharp edges and where the slope of the roof changes. The discrepancies are because in the wind-tunnel experiments, the pressure coefficients were not recorded in the overhang portions and at the sharp bends. In these regions the pressure coefficients were either interpolated or extrapolated. Overall the trends of the contours plotted for different wind attack angle as well as the numerical values remains approximately the same as that of the contour plot of Shakeel et al and $\mathrm{Xu}$ et al.

For $45^{\circ}$ degree wind attack angle, the experimental (wind-tunnel) values of pressure coefficients (suction) are less in comparison to CFD simulated values. Whereas for the case of $0^{\circ}$ and $90^{\circ}$ wind attack angle the wind-tunnel values of pressure coefficients (suction) are higher than the CFD simulated values.

In Figures 11 to 13, comparison of pressure coefficients obtained using the CFD techniques and the wind tunnel data, along the rakes (as shown above the figure) on the hip-roof, have been made. At zero degree wind incidence angle, in the windward region, pressure coefficient values of both SKE and RNGKE fall apart from that of the wind tunnel values. However, in the leeward region RNGKE gives reasonably good values. Whereas, at $45^{\circ}$ and $90^{\circ}$ wind incidence angle, the results obtained from CFD simulation remains in good agreement with that of wind tunnel data, except near ridge where both analytical and experimental values fall apart. This is due to the reason that wind tunnel values were extrapolated in that region and no observation has been made directly. Pressure coefficient obtained from the Standard k- $\varepsilon$ method and the RNG k- $\varepsilon$ method on the roof of the hip-roof building is shown in the Figures 14 to 20. The details of the comparison can be seen in the Table 2.

It has been found that the Standard $k-\varepsilon$ models have a good reputation for its efficiency and easy implementation. It has been recognized that the widely used Standard $k-\varepsilon$ model can predict the general wind conditions around the building reasonably well, except those in the separated regions above roof surface. This can be attributed to the overestimation of turbulence energy where the slope of the roof changes. It can be seen from the Table 2 that the pressure coefficients obtained from the Standard $k-\varepsilon$ models are more than the RNG $k-\varepsilon$ turbulence models. The maximum pressure coefficient on the roof has been found for $45^{0}$ wind incidence angle and the least for $90^{\circ}$ wind incidence angle.

The RNG $k-\varepsilon$ turbulence model was found to be the best choice among the RANS models for rapid solutions. It gave encouraging results for the mean pressure coefficients in most cases. Accurate modeling of the boundary conditions on the incident flows such as the velocity profile and turbulence intensity profile in the numerical simulations is of great importance for getting good agreement between the numerical results and experimental measurements.

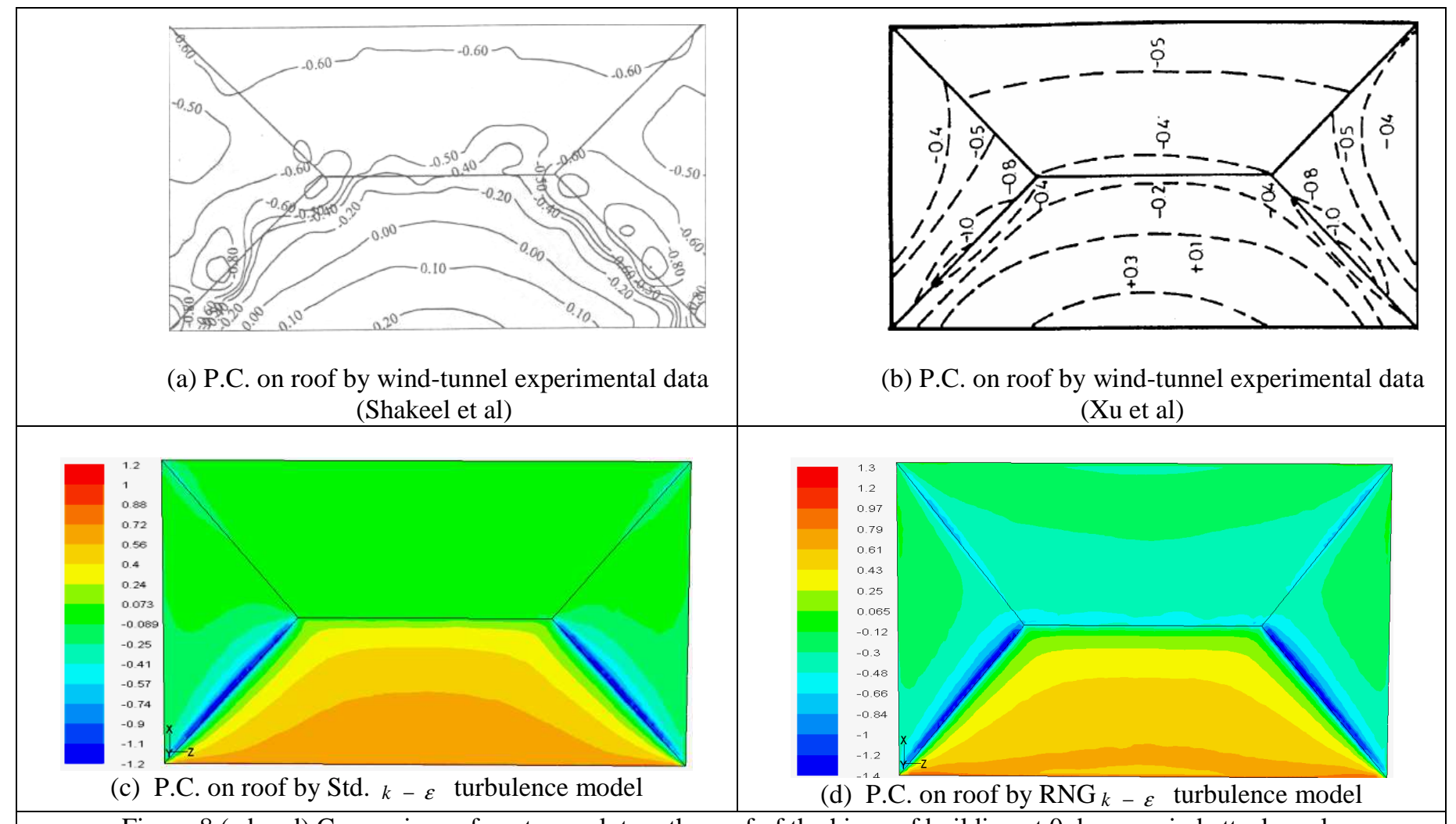

Figure 8 (a,b,c,d) Comparison of contours plot on the roof of the hip-roof building at 0 degree wind attack angle 


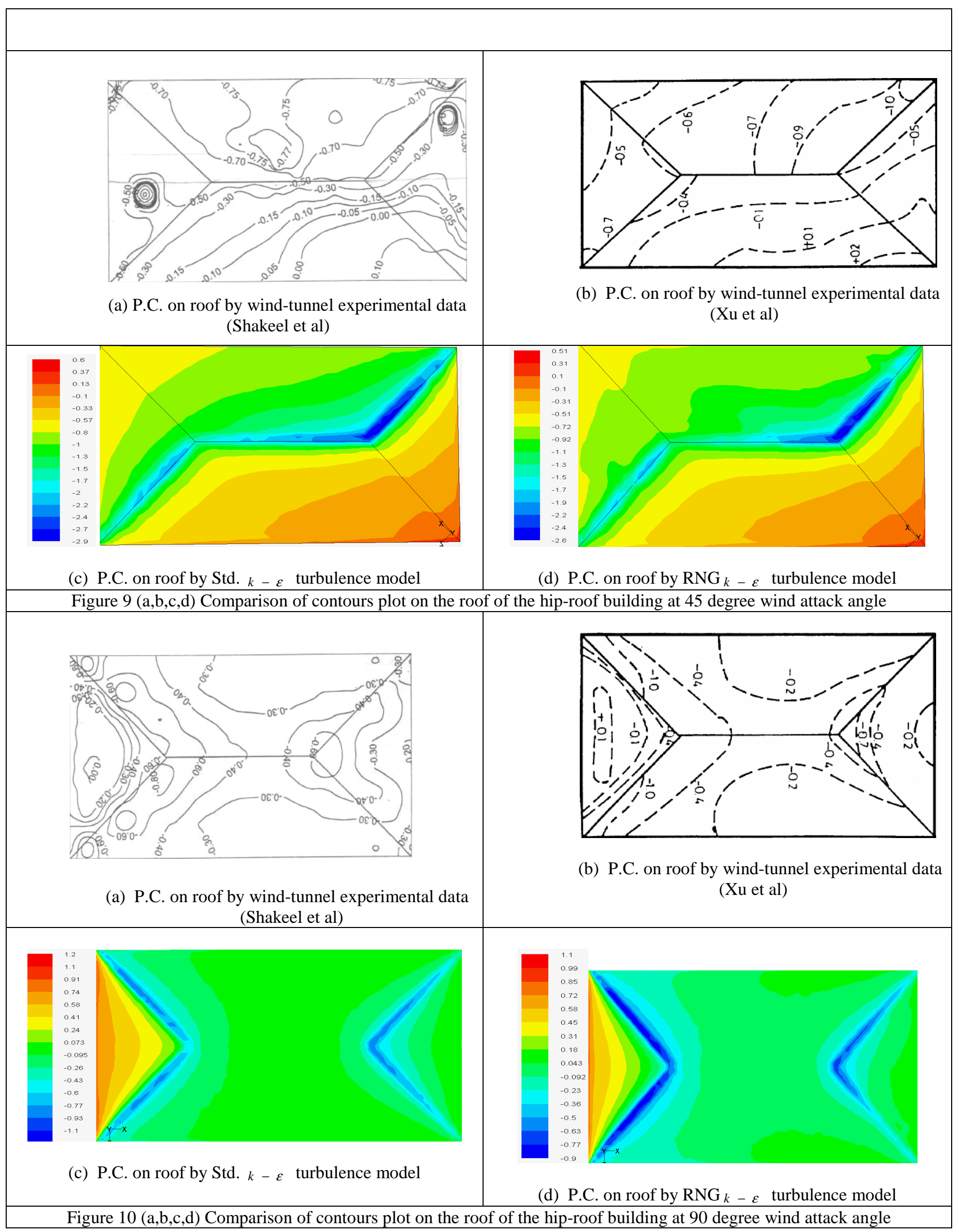




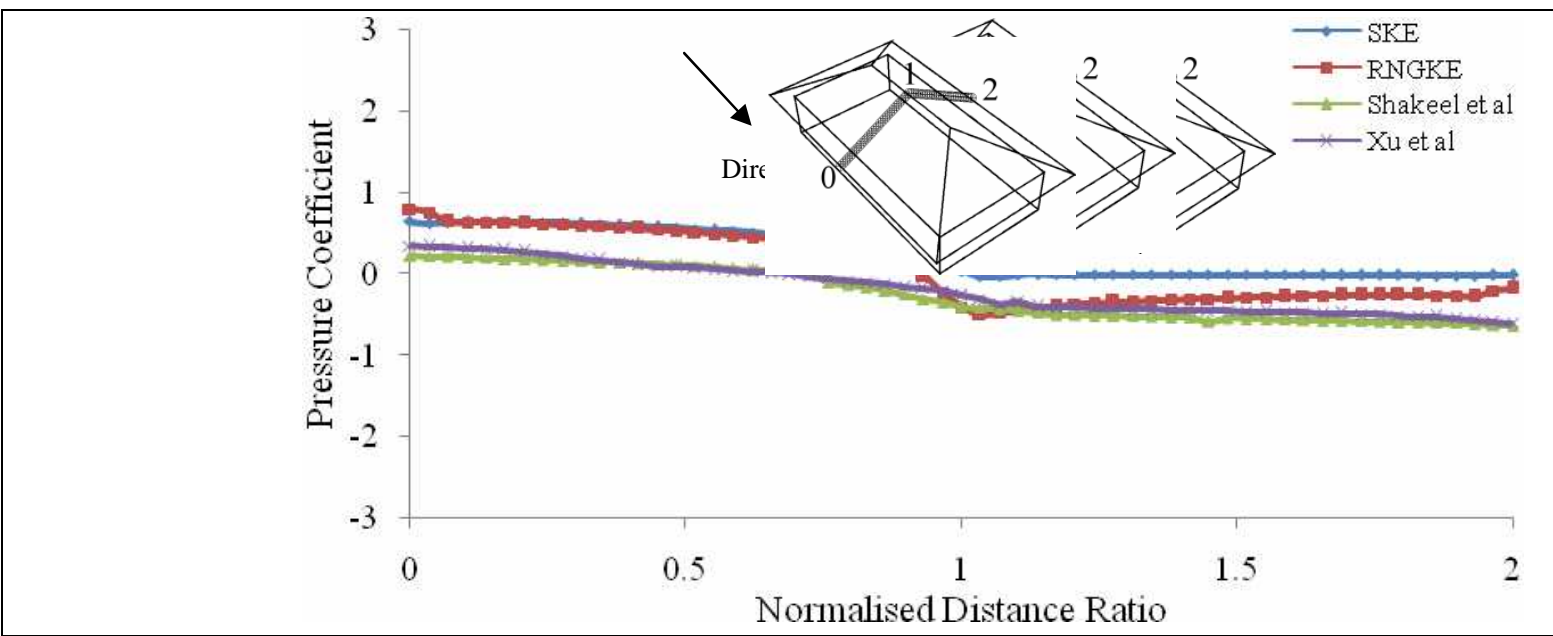

Figure 11 Plot of Pressure Coefficients along the rake on the roof of the hip-roof building at zero degree wind attack angle

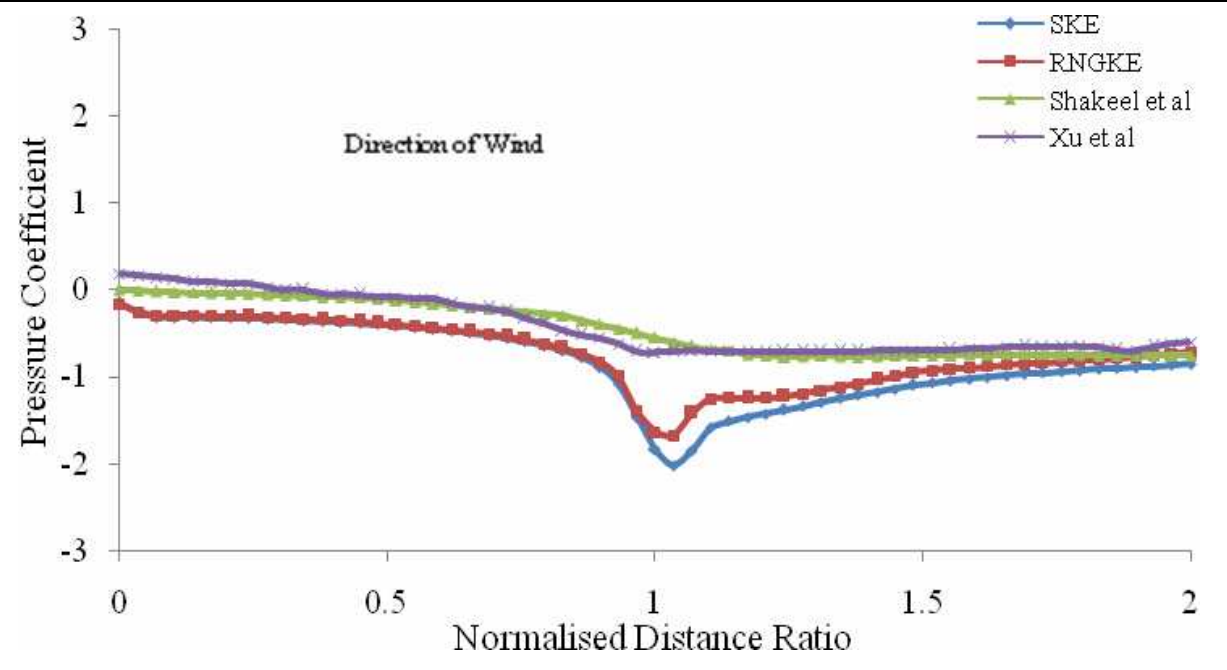

Figure 12 Plot of Pressure Coefficients along the rake on the roof of the hip-roof building at 45 degree wind attack angle

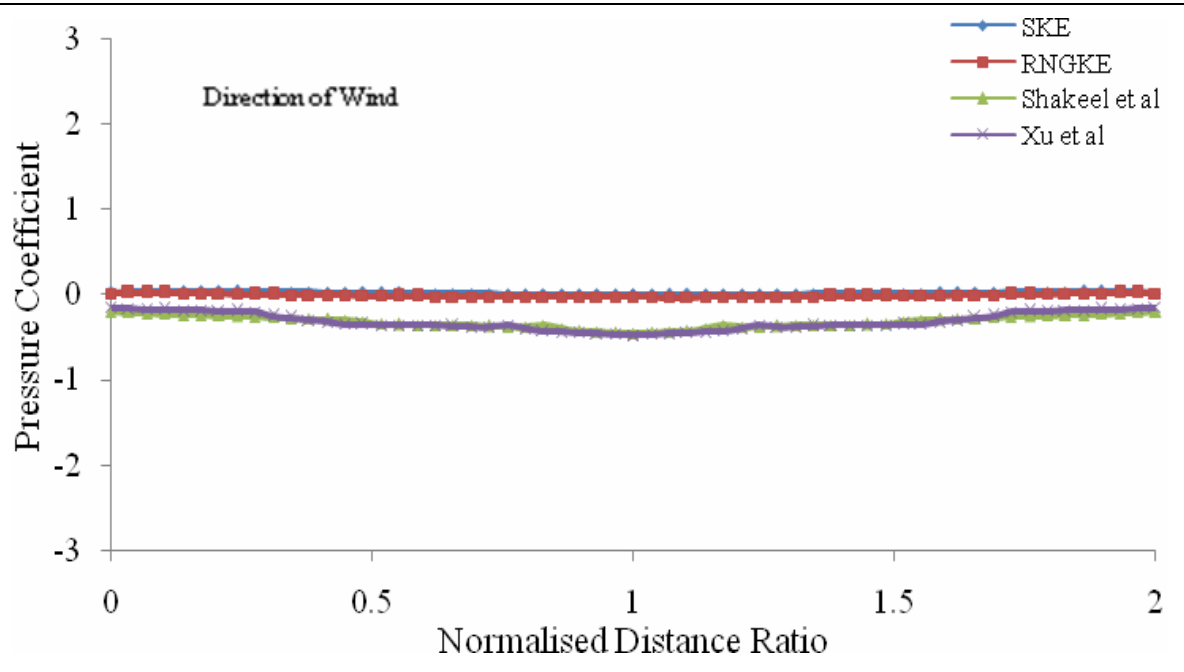

Figure 13 Plot of Pressure Coefficients along the rake on the roof of the hip-roof building at 90 degree wind attack angle 


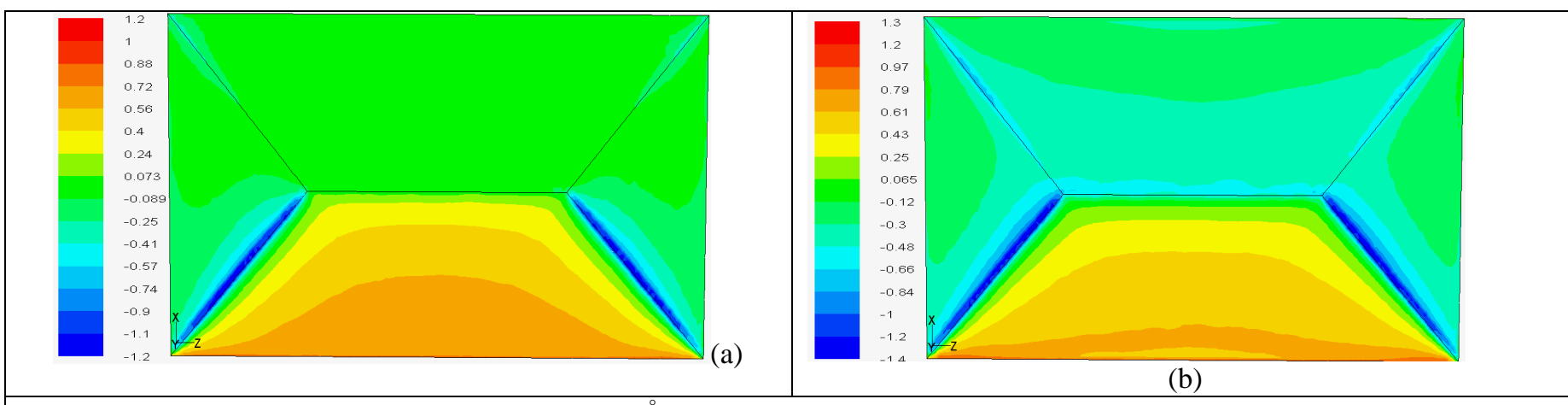

Figure 14 (a,b) Pressure coefficients on the roof at $0^{\circ}$ of wind incidence using the Standard $k-\varepsilon$ and the RNG $k-\varepsilon$ turbulence model respectively

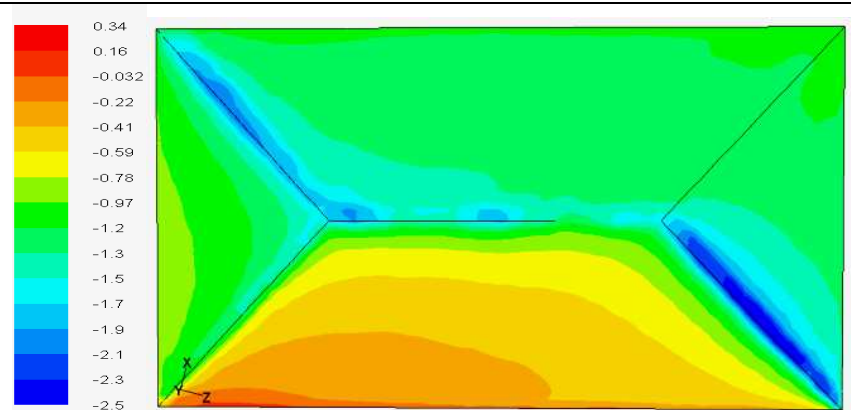

(a)

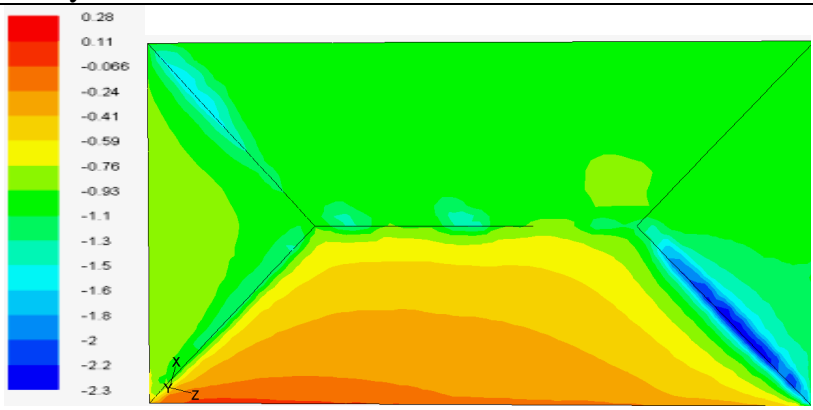

(b)

Figure 15 (a,b) Pressure coefficients on the roof at $15^{\circ}$ of wind incidence using the Standard $k-\varepsilon$ and the RNG $k-\varepsilon$ turbulence model respectively

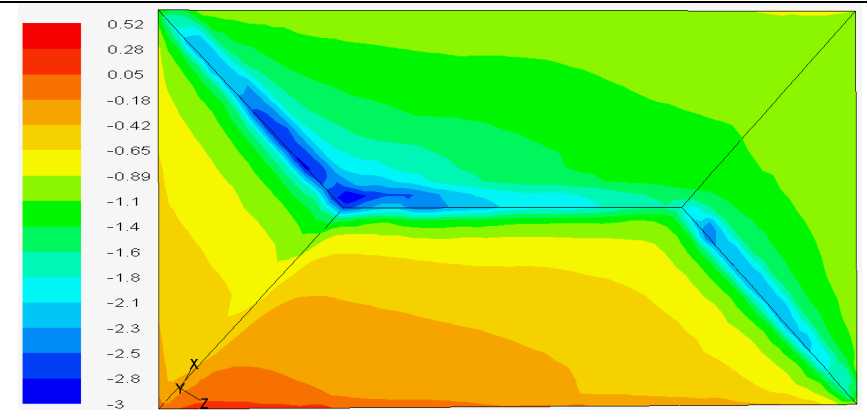

(a)

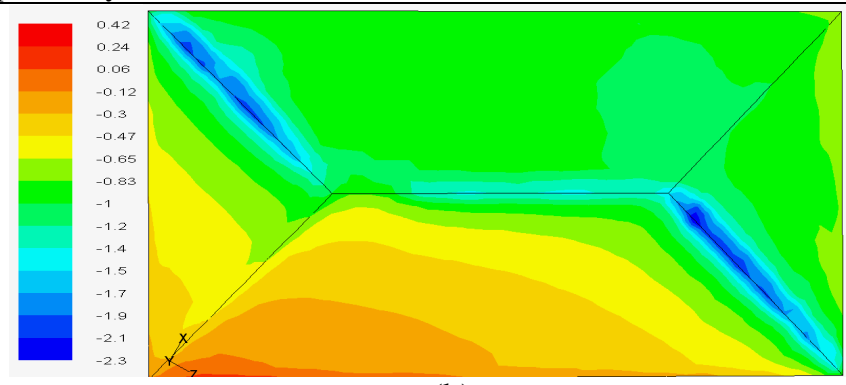

(b)

Figure 16 (a,b) Pressure coefficients on the roof at $30^{\circ}$ of wind incidence using the Standard $k-\varepsilon$ and the RNG $k-\varepsilon$ turbulence model respectively

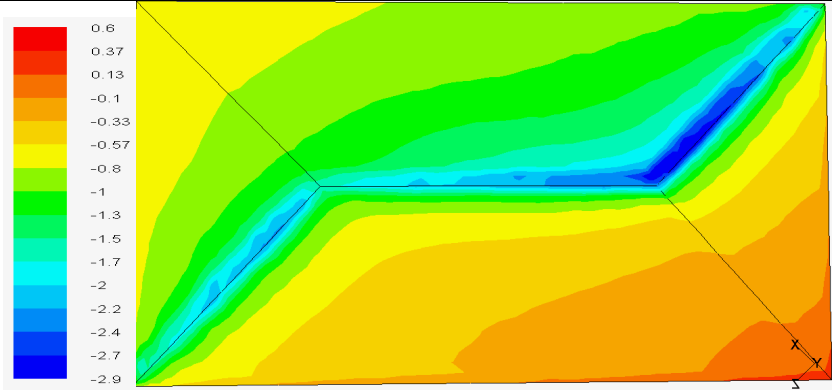

(a)

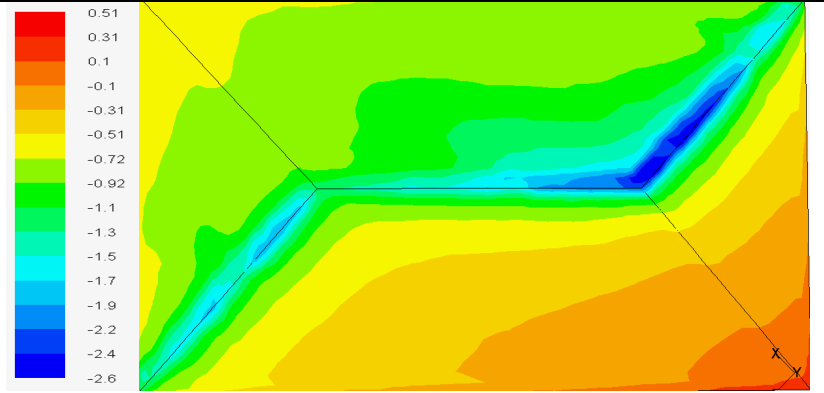

(b)

Figure 17 (a,b) Pressure coefficients on the roof at $45^{\circ}$ of wind incidence using the Standard $k-\varepsilon$ and the RNG $k-\varepsilon$ turbulence model respectively 


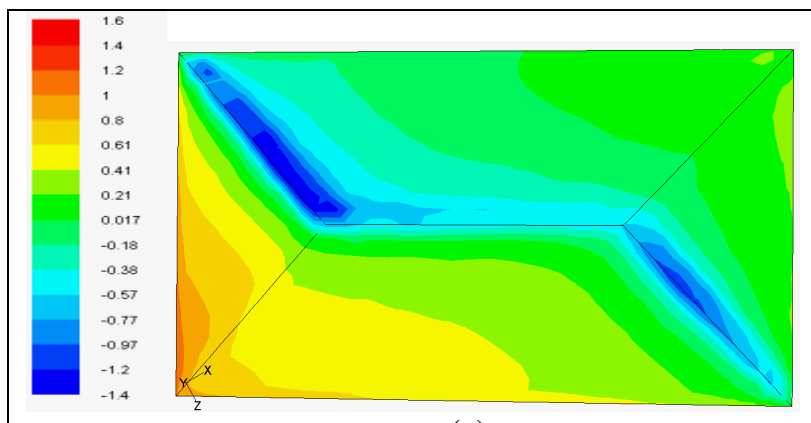

(a)

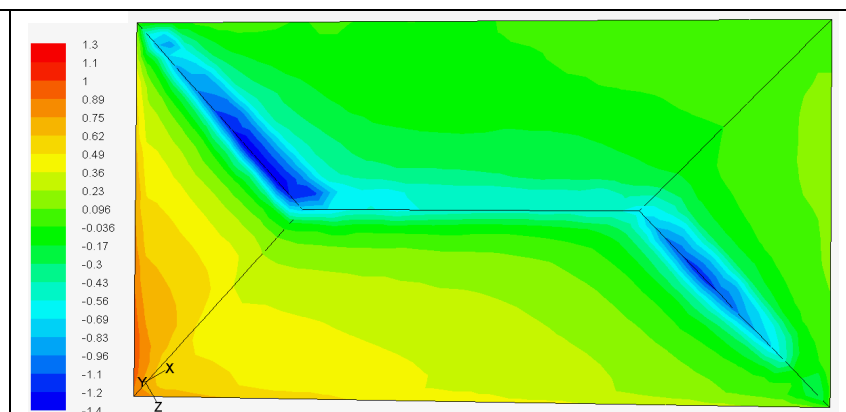

(b)

Figure $18(\mathrm{a}, \mathrm{b})$ Pressure coefficients on the roof at $60^{\circ}$ of wind incidence using the Standard $k-\varepsilon$ and the RNG $k-\varepsilon$ turbulence model respectively

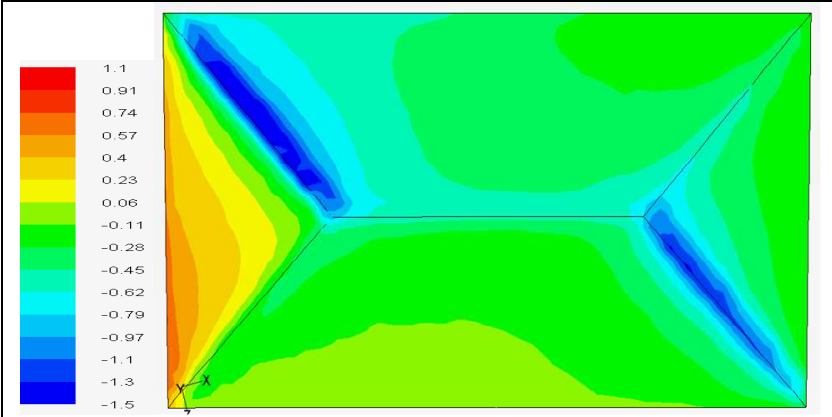

(a)

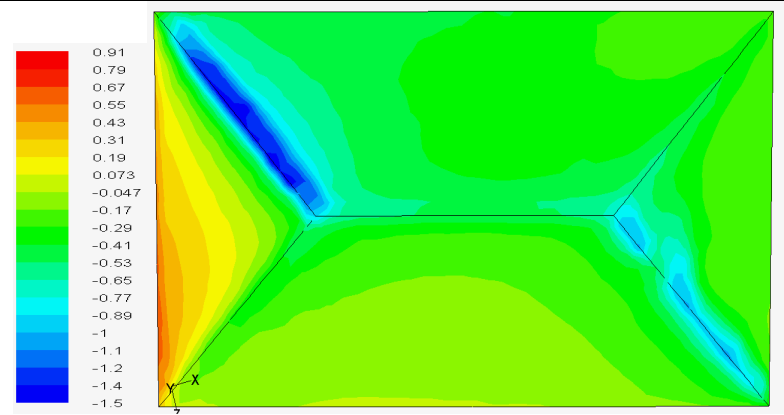

(b)

Figure 19 (a,b) Pressure coefficients on the roof at $75^{\circ}$ of wind incidence using the Standard $k-\varepsilon$ and the RNG $k-\varepsilon$ turbulence model respectively

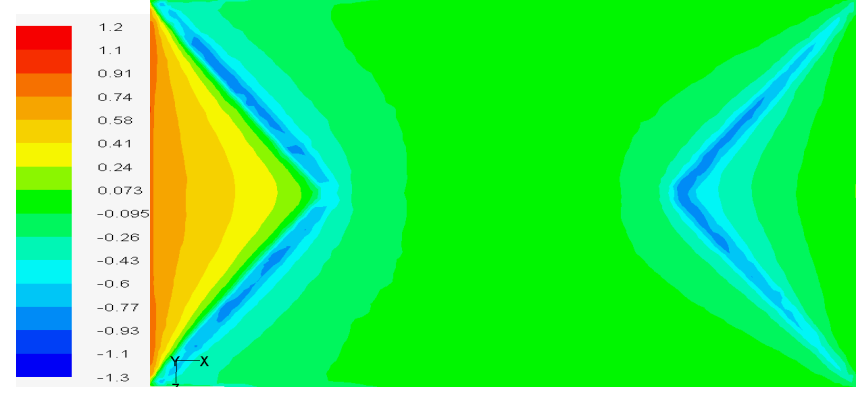

(a)

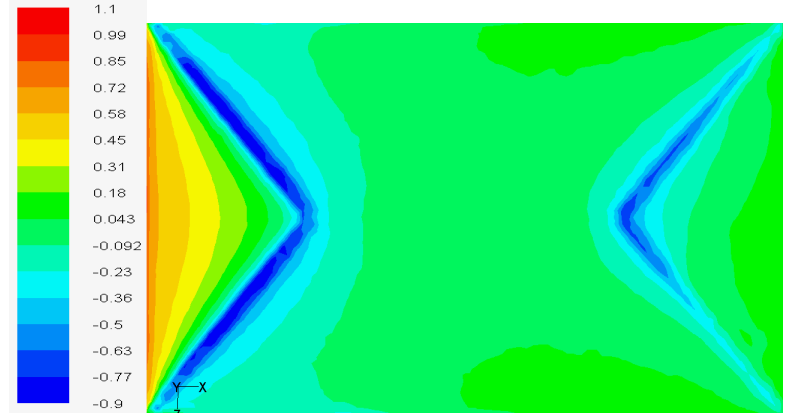

(b)

Figure 20 (a,b) Pressure coefficients on the roof at $90^{\circ}$ of wind incidence using the Standard $k-\varepsilon$ and the RNG $k-\varepsilon$ turbulence model respectively

\section{Conclusions}

In the hip roof building, the slope of the roof changes along all four outer walls. Because of the presence of these sharp edges and corners, there is an over production of turbulent kinetic energy near these edges and corners. This is the reason why the standard $k-\varepsilon$ over predicts the pressure coefficients. Critical angle of wind attack is found to be $45^{\circ}$, having maximum negative value of pressure coefficient on roof. Among the CFD Codes used, the RNG $k-\varepsilon$ method seems to be in close proximity with the experimental work. Suitable turbulence model for wind engineering should be used to model the turbulent flow.

The maximum and minimum values of wind pressure coefficients do not match exactly with the values of wind tunnel data near edges and bends, because near sharp edges and corners, the wind tunnel data is not available. The values of the wind pressure coefficients in these regions are either interpolated or extrapolated from the neighboring data. The pressure taps in those regions cannot fixed.

To get more accurate results near to the wind-tunnel data, it should be simulated with more enhanced CFD codes such as DES, LES and DNS. Modeling of the boundary conditions of incident flows such as the velocity profile and turbulence intensity profile in the numerical simulations should be accurate enough to keep good agreement between the numerical and experimental data.

Development work on CFD code has witnessed the successful implementation and testing of methods for modeling turbulence and fluid flow mechanism. Encouraging results have been found using CFD techniques. Both the wind-tunnel tests and CFD techniques are complementary and are still advancing. Improvements are needed for CFD applications in wind engineering, including grid generation strategies for complex solution domain, application of higher order of numerical schemes for space and 
time discretization, more general and reliable sub-grid scale turbulence models for LES, more accurate and realistic methods for generation of inflow boundary turbulence characteristics, etc.

\section{Abbreviations:}

CFD: Computational Fluid Dynamics

DNS: Direct Numerical Simulation

MMK: Murakami, Mochida and Kondo

RANS: Reynolds Averaged Navier-Stokes Equations

SKE: Standard $k-\varepsilon$

\author{
DES: Direct Eddy Simulation \\ LES: Large Eddy Simulation \\ P.C.: Pressure Coefficients \\ RNG: Renormalization group (RNG) $k-\varepsilon$
}

\section{References}

Ahmad, S., Kumar, K. 2002. Effect of Geometry on Wind Pressures on Low-rise Hip Roof Buildings. Journal of Wind Engineering and Industrial Aerodynamics, Vol. 90, pp. 755-779.

Blocken, B.J.E., Stathopoulos, T., Carmeliet, J.E., Hensen, J.L.M. 2009. Application of CFD in Building Performance Simulation for the Outdoor Environment. Proceedings of the 11th IBPSA Building Simulation Conference, Glasgow, Scotland, July 27-30, pp 489-496.

Bitsuamlak, G.T., Stathopoulos, T. and Bédard, C. 2004. Numerical Evaluation of Wind Flow over Complex Terrain: Review. Journal of aerospace engineering, ASCE, Vol. 17, No. 4 (October), pp. 135-145.

Bureau of Indian Standard IS: 875 (Part 3), Code of Practice for Design Loads (Other than Earthquake) for Building and Structures, 1987.

Fluent. Inc. The user guide of Fluent, 6.2.3, 2006.

Gambit. Inc. The user guide of Gambit,2.6, 2006.

He, P., Katayama, T., Hayashi, T., Tsutsumi, J., Tanimoto, J., Hosooka, I. 1997. Numerical Simulation of Air Flow in an Urban Area with Regularly Aligned Blocks. J. Wind Eng. \& Ind. Aerodyn. Vol. 67 \& 68, pp. 281-291.

Huang, S., Li, Q.S., Xu, S. 2007. Numerical Evaluation of Wind Effects on a Tall Steel Building by CFD. Journal of Constructional Steel Research, Vol. 63, pp. 612-627.

Launder B.E. and Spalding D.B. 1972. 'Mathematical model of turbulence', Academic Press Inc. (London) Limited, U.K.

Lien, F.S., Yeeb, E., Cheng, Y. 2004. Simulation of Mean Flow and Turbulence Over a 2D Building Array Using High-Resolution CFD and a Distributed Drag Force Approach. J. Wind Eng. \& Ind. Aerodyn. Vol. 92, pp. 117-158.

Meecham, D., Surry, D. and Davenport, A.G. 1991. 'The magnitude and distribution of wind-induced pressures on hip and gable roofs', Journal of Wind Engineering and Industrial Aerodynamics, Vol. 38, pp. 257-272.

Murakami S. 1998. Overview of turbulence models applied in CWE-1997. Journal of Wind Engineering and Industrial Aerodynamics, Vol. 74-76, pp. 1-24.

Taher, R. 2010. General Recommendations for Improved Building Practices in Earthquake and Hurricane Prone Areas. Prepared in the aftermath of the Haiti earthquake of 2010 for Architecture for Humanity, San Francisco, California, USA.

Tsou, J. 2001. Strategy on Applying Computational Fluid Dynamic for Building Performance Evaluation', Automation in Construction, Vol. 10, pp. 327-335.

Xu, Y.L. Reardon, G.F. 1998. Variations of wind pressure on hip roofs with roof pitch. Journal of Wind Engineering and Industrial Aerodynamics, Vol. 73, pp. 267-284.

Yakhot V. and Orszag S.A. 1986. 'Renormalization Group Analysis of Turbulence: I. Basic Theory', Journal of Scientific Computing, Vol. 1, No. 1, pp. 3-51.

Zhang, A.S., Gao, C.L., Zhang, L. 2005. Numerical Simulation of the Wind Field Around Different Building Arrangements. J. Wind Eng. Ind \&. Aerodyn, Vol. 93, pp. 891-904.

\section{Biographical notes}

Azhar Jameel is an Associate Professor, Civil Engineering Section, University Polytechnic, Aligarh Muslim University, Aligarh, India, having more than twenty five years of teaching and research experience. Areas of research are masonry structures, Computational Fluid Dynamics and Wind engineering.

Dr. Hassan Irtaza, Associate Professor, Department of Civil Engineering, Aligarh Muslim University, Aligarh, India. Ph.D. awarded from Oxford Brookes University, Oxford, U.K. in the area of Wind Engineering and Computational Fluid Dynamics and having teaching and research experience of more than twenty years. Areas of research are Wind engineering, Earthquake engineering and Structural Dynamics

M.A. Javed is Research Associate in the Department of Civil Engineering, Aligarh Muslim University, Aligarh, India.

Received August 2014

Accepted February 2014

Final acceptance in revised form May 2015 